\title{
Evaluation of Antioxidant Potential in Different Parts of Genus Musa Species
}

\author{
Kalai Selvi.P \\ Revathi Babu P K S \\ Ananda Boopathy.M
}

\begin{abstract}
Antioxidants play a very important role in the defense against the damage caused by free radicals in the body. Free radicals are produced in the body either naturally or on the exposure of radiation, cigarette smoke, etc. and can be implicated in many diseases like cancer, atherosclerosis, arthritis, Parkinson's disease, Alzheimer's disease and can also be held responsible for aging and other age-related diseases. The body can produce antioxidants to aid in its defense against free radical damage. But in most cases dietary supplement of antioxidants is recommended. Fruits and their parts are a very good source of antioxidants and other nutrients. Though their potency as antioxidants has been studied, comparative analysis is yet to be performed. This project aims to evaluate and compare antioxidant activity of the three parts of banana varieties namely, Rasthali leaf, Rasthali stem, Rasthali flower, Karpooravalli leaf, Karpooravalli stem, Karpooravalli flower. Ethanolic extraction was performed for the parts of banana varieties and the extracts were subjected to in vitro free radical scavenging assays, enzymatic, nonenzymatic and phytochemical components assays. Total antioxidant assay was also carried out to initially confirm the antioxidant potential. The results were obtained for the parts of Musa spp and they were found to possess significant antioxidant potential with leaf part having the highest activity comparatively.
\end{abstract}

\section{INTRODUCTION}

A free radical is any atom or molecule that has a single unpaired electron in an outer shell. While a few free radicals such as melanin are not chemically reactive, most biologically-relevant free radicals are highly reactive. For most biological structures, free radical damage is closely associated with oxidative damage. Antioxidants are reducing agents, and limit oxidative damage to biological structures by passivating free radicals.

Free-radical damage occurs on an atomic level. Molecules are made of atoms, and a single atom is made up of protons, neutrons, and electrons. Electrons are always found in pairs. However, when oxygen molecules are involved in a chemical reaction, they can lose one of their electrons. This oxygen molecule that now only has one electron is called a free radical. With only one electron, the oxygen molecule must quickly find another electron, and it does this by taking the electron from another molecule. When that molecule in turn loses one of its electrons, it too must seek out another, in a continuing reaction. Molecules attempting to repair themselves in this way trigger a cascading event called "free-radical damage."

Chain reactions involving free radicals can usually be divided in to three distinct processes: initiation, propagation, and termination. Initiation reactions are those that result in a net increase in the number of free radicals. They may involve the formation of free radicals from stable species. They may involve reactions of free radicals with stable species to form more free radicals. Propagation reactions are those reactions involving free radicals in which the total number of free radicals remains same. Termination reactions are those reactions resulting in a net decrease in the number of free radicals. Typically two free radicals combine to form a more stable species.

Their destructive effects on proteins may play a role in the causation of cataracts. Free radical damage to DNA is also implicated in the causation of cancer and its effect on LDL cholesterol is very likely responsible for heart disease. In fact, the theory associating free radicals with the aging process has also gained widespread acceptance.

If free radicals are not inactivated, their chemical reactivity can damage all cellular macromolecules including proteins, carbohydrates, lipids and nucleic acids.

Although oxidation reactions are critical for life, they also result in cell damage which, research shows manifests in ageing. Other research is on the investigation on the role of antioxidants in the treatment of many diseases like cancer, Alzheimer's disease, Parkinson's disease, and amyotrophic lateral sclerosis. Animals maintain complex systems of multiple types of antioxidants, such as Vitamin A, Beta Carotene and Vitamin E. 
Antioxidants are compounds capable of slowing or preventing the oxidation of other molecules. They are also known as free radical scavengers of the body for their ability to terminate chain oxidation reactions in two ways - by removing radical intermediates and by getting oxidised themselves.

There are several enzyme systems within the body that scavenge free radicals, the principle micronutrient (vitamin) antioxidants are Vitamin E, Beta Carotene, and Vitamin C. Different Antioxidants work in different ways. Beta carotene plays a major role in protein synthesis, when it is converted to fat-soluble Vitamin A. It helps in maintaining healthy skin. Vitamin C prevents skin damage and helps build collagen, the fibrous protein that gives skin elasticity. Vitamin E protects the body tissues from damage by harmful free radicals. Apart from vitamins, selenium, a trace metal is also required for proper functioning of the body's antioxidant enzyme systems.

\section{RESULTS AND DISCUSSION}

Free radicals are atoms, molecules, or ions with unpaired electrons on an open shell configuration. The unpaired electrons cause them to be highly chemically reactive. Radicals play an important role in combustion, atmospheric chemistry, polymerization, plasma chemistry, biochemistry, and many other chemical processes, including human physiology.

An antioxidant is a molecule capable of slowing or preventing the oxidation of other molecules. Oxidation is a chemical reaction that transfers electrons from a substance to an oxidizing agent. Oxidation reactions can produce free radicals, which start chain reactions that damage cells. Antioxidants terminate these chain reactions by removing free radical intermediates, and inhibit other oxidation reactions by being oxidized themselves. As a result, antioxidants are often reducing agents such as thiols, ascorbic acid or polyphenols.

Oxidative stress has been implicated in the pathology of many diseases, inflammatory conditions, cancer and aging. And the best way to eliminate free radicals is with the help of antioxidants like Vitamins A, E and C. Antioxidants may offer resistance against oxidative stress by scavenging the free radicals, inhibiting lipid peroxidation, etc. and thus prevent the onset of deadly diseases.

Literature suggests that antioxidant activity is high on herbal plants and vegetables. Fruits and vegetables are rich in many nutrients. Green leafy vegetables are highly rich in nutrients like Vitamin A and Vitamin C, which are potent non-enzymatic antioxidants. Studies carried out by researchers have however shown that low consumption of vegetables is associated with an increased risk of cancer. This clearly indicates that apart from the antioxidants synthesized naturally, the body requires a supplement of dietary antioxidants. This can be obtained only by the consumption of an antioxidant rich diet.

Antioxidants are those substances that when present in low concentrations compared to those of an oxidizable substrate significantly delays or prevents oxidation of that substance. Antioxidants may inhibit these deleterious effects of ROS on the organism and therefore, a number of studies have evaluated the effect of various antioxidants in vitro and in vivo studies.

\section{FREE RADICAL SCAVENGING ASSAYS}

\subsubsection{Total antioxidant capacity assay}

The total antioxidant activities of various parts of Musa spp extracts are depicted in Table 3.1.1.1. The total antioxidant assay gives an estimate of the overall antioxidant potential of parts of the Musa spp. There is a formation of phosphomolybdenum complex, the intensity of which indicates the potential of the peel as a scavenger of free radicals. The total antioxidant capacity of parts of the Musa spp extracts was expressed as number of equivalents of ascorbic acid.

Values represent mean $\pm \mathrm{SD}$ of 3 replicates.

Means followed by a common letter are not significantly different at the 5\% level by DMRT.

Different parts extracts exhibited various degrees of antioxidant capacity . The ethanolic extract of Rasthali leaf showed higher activity in the range of $5.69 \mathrm{mM} \mathrm{g}^{-1}$ in comparison to other parts of Musa spp, whereas the ethanolic extract of Karpooravalli stem showed least activity.

3.1.2. DPPH radical scavenging activity

DPPH is nitrogen centered free radical that shows strong absorbance at $517 \mathrm{~nm}$. Deep violet coloured methanolic DPPH solution changes to yellow colour in presence of DPPH radical scavengers. DPPH radical accepts an electron or hydrogen radical to become a stable diamagnetic molecule. Extent of DPPH radical scavenged was determined by the decrease in intensity of violet colour in the form of $\mathrm{EC}_{50}$ values. Lower $\mathrm{EC}_{50}$ value represents higher antioxidant activity. The antioxidant activity was compared with ascorbic acid as standard Yamaguchi et al., (1998). 
Figure 3.1.3.1. Scavenging activity (\%) on ABTS radical by ethanolic extracts of parts of Rasthali variety.

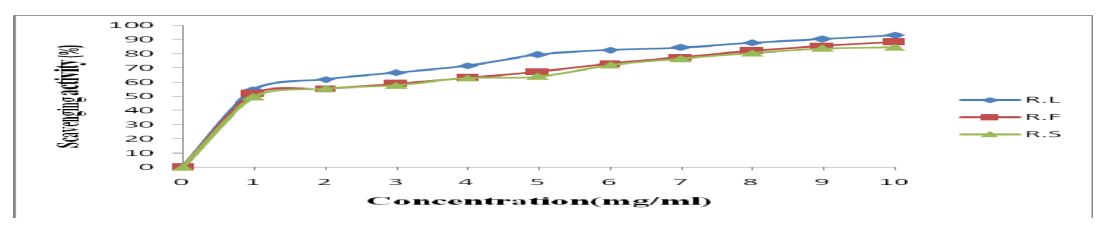

Figure 3.1.3.2. Scavenging activity (\%) on ABTS radical by ethanolic extracts of parts of Karpooravalli variety.

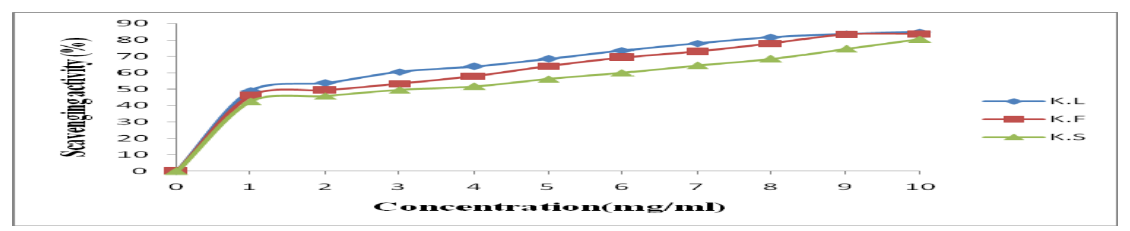

Figure 3.1.3.3 Comparison of EC50 values of ABTS radical scavenging activity

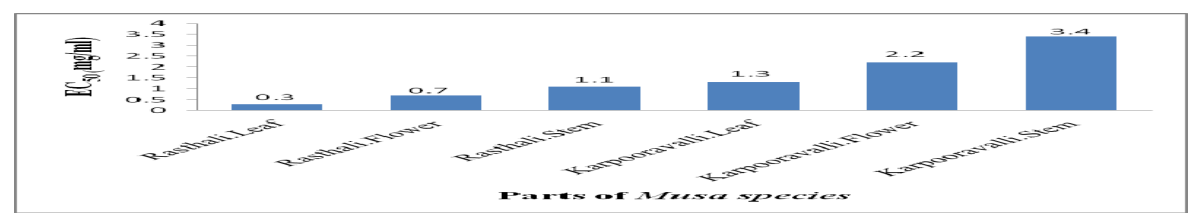

Free radical scavenging potential of the ethanolic extracts of parts of Musa spp is shown in Table 3.1.3.1 which increases with the increase in concentration

At $1-10 \mathrm{mg} \mathrm{ml}^{-1}$, the ethanolic extract of Rasthali leaf, flower, stem and karpooravalli leaf, flower, stem shows the percentage inhibition of $54.72 \%-93.18 \%, 52.04 \%-88.36 \%, 49.76 \%-84.60 \%, 48.83 \%-84.76 \%$, 45.95\%-83.94\%, 42.46\%-80.42\% respectively. However, at $10 \mathrm{mg} \mathrm{ml}^{-1}$, Rasthali leaf extract exhibited highest ABTS scavenging activity. With respect to the $\mathrm{EC}_{50}$ value of Rasthali leaf showed least value, which represent highest antioxidant activity. Statistically, the scavenging activity of antioxidants was effective in the order of Rasthali leaf $>$ Rasthali flower $>$ Rasthali stem $>$ Karpooravalli leaf $>$ karpooravalli flower $>$ karpooravalli stem. 3.1.4. Nitric oxide radical scavenging activity

Nitric oxide is a free radical produced in mammalian cells, and is involved in the regulation of various physiological processes. However, excess production of NO is associated with several diseases (Ross, 1993; Ialenti et al., 1993). Oxygen reacts with excess NO to generate nitrite and peroxynitrite anions, which act as free radicals (Cotran et al., 1999).

Extent of nitric oxide radical scavenged was determined by the decrease in intensity of pink coloured chromophore in the form of $\mathrm{EC}_{50}$ values at $546 \mathrm{~nm}$. Lower $\mathrm{EC}_{50}$ value represents higher antioxidant activity.

Figure 3.1.4.1. Scavenging activity (\%) on nitric oxide radical by ethanolic extracts of parts of Rasthali variety.

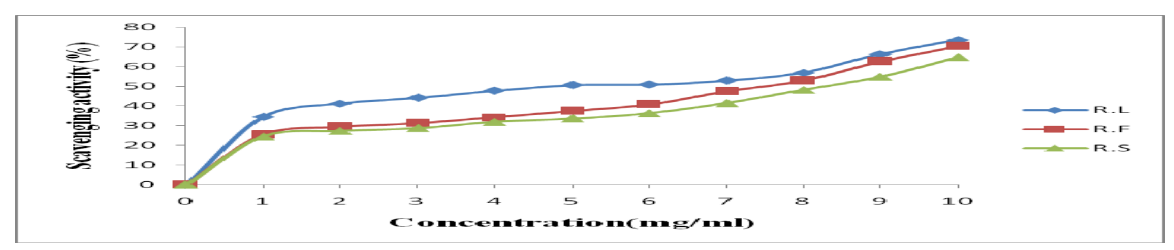

Figure 3.1.4.2. Scavenging activity (\%) on nitric oxide radical by ethanolic extracts of parts of Karpooravalli variety.

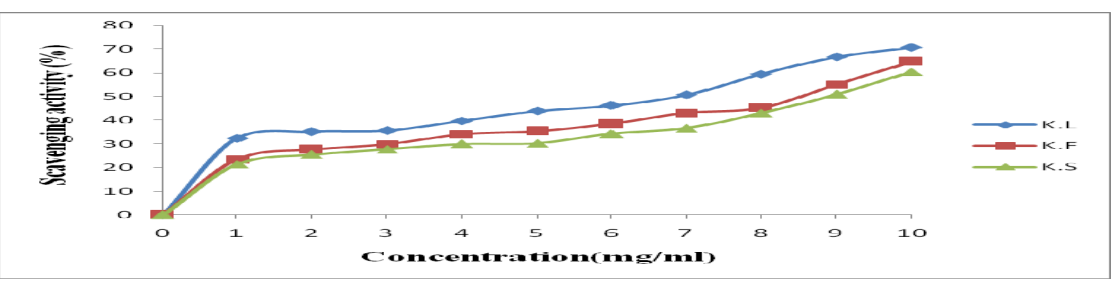


Figure 3.1.4.3. Comparison of EC50 values of nitric oxide radical inhibition activity

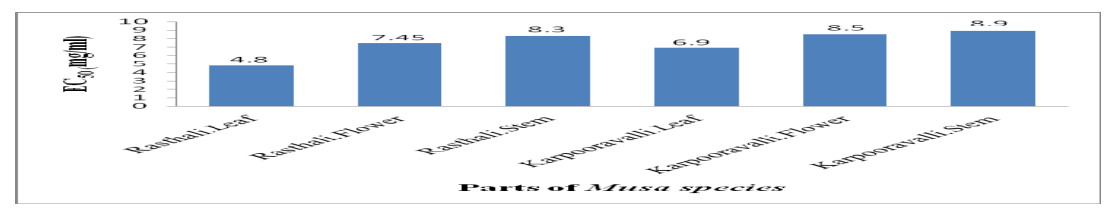

Free radical scavenging potential of the ethanolic extracts of parts of Musa spp is shown in Table 3.1.4.1 which increases with the increase in concentration

At $1-10 \mathrm{mg} \mathrm{ml}^{-1}$, the ethanolic extract of Rasthali leaf, flower, stem and karpooravalli leaf, flower, stem shows the percentage inhibition of $34.42 \%-73.58 \%, 25.41 \%-70.37 \%, 24.49 \%-64.66 \%, 32.45 \%-70.66 \%$, $23.52 \%-64.77 \%, 21.32 \%-60.45 \%$ respectively. However, at $10 \mathrm{mg} \mathrm{ml}^{-1}$, Rasthali leaf extract exhibited highest nitric oxide scavenging activity. With respect to the $\mathrm{EC}_{50}$ value, Rasthali leaf showed least value, which represent highest antioxidant activity. Statistically, the scavenging activity of antioxidants was effective in the order of Rasthali leaf $>$ Karpooravalli leaf $>$ Rasthali flower $>$ karpooravalli flower $>$ Rasthali stem $>$ karpooravalli stem.

\subsubsection{Hydroxyl radical scavenging activity}

The ability of extracts to scavenge $\mathrm{OH}$ radical was assessed using the classic deoxyribose degradation assay described by Halliwell et al (2007). When EDTA chelated iron- (III) ions are incubated with reducing agent and $\mathrm{H} 2 \mathrm{O} 2$ in the assay, $\mathrm{OH}$ radicals are generated in free solution that attack the deoxyribose substrate and fragmenting it into TBARS. The generated TBARS reflect the extent of generation of OH. Extent of hydroxyl radical scavenged was determined by the decrease in intensity of pink coloured chromophore in the form of EC50 values which was determined at 532nm. Lower EC50 value represents higher antioxidant activity.

Figure 3.1.5.1. Scavenging activity (\%) on hydroxyl radical by ethanolic extracts of parts of Rasthali variety.

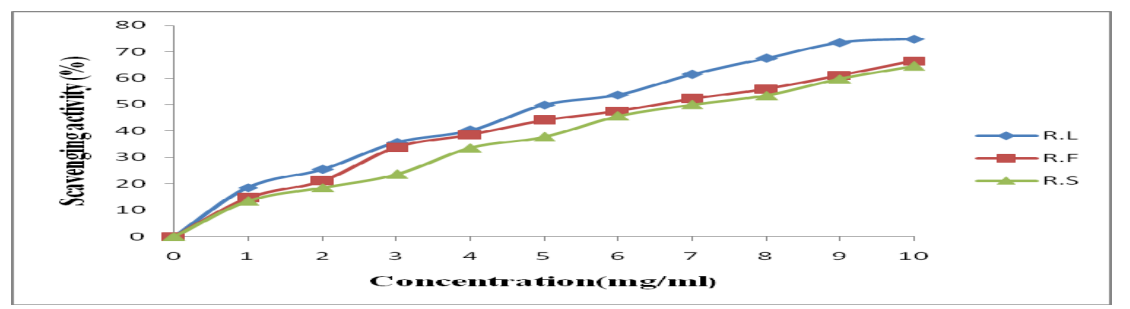

Figure 3.1.5.2. Scavenging activity (\%) on hydroxyl radical by ethanolic extracts of parts of Karpooravalli variety.

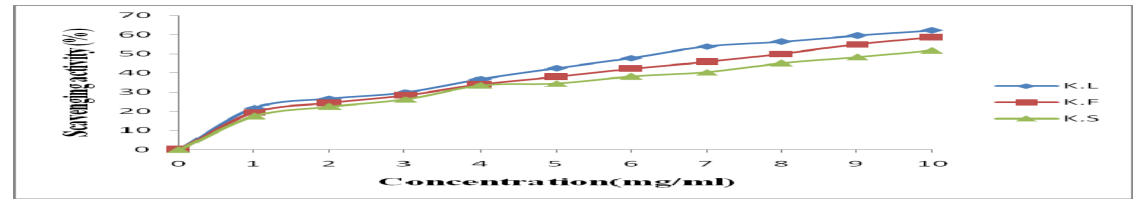

Figure 3.1.5.3 Comparison of EC50 values of hydroxyl radicals inhibition activity

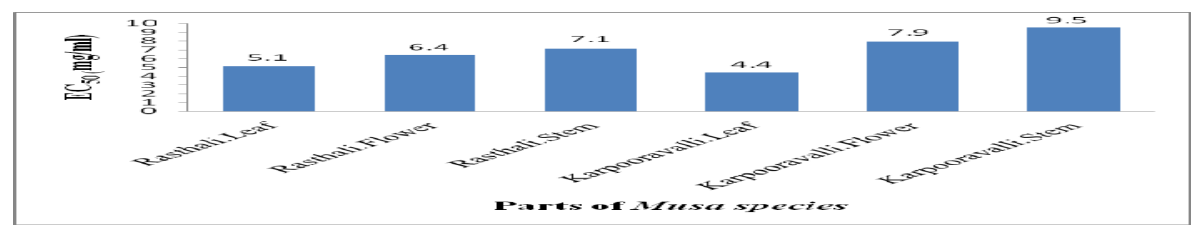

Free radical scavenging potential of the ethanolic extracts of parts of Musa spp is shown in Table 3.1.5.1 which increases with the increase in concentration

At $1-10 \mathrm{mg} \mathrm{ml}^{-1}$, the ethanolic extract of Rasthali leaf, flower, stem and karpooravalli leaf, flower, stem shows the percentage inhibition of $18.54 \%-74.79 \%, 14.59 \%-66.51 \%, 13.43 \%-64.54 \%, 21.73 \%-62.20 \%$, 19.44\%-58.73\%, 17.55\%-51.82\%, respectively. However, at $10 \mathrm{mg} \mathrm{ml}^{-1}$, Rasthali leaf extract exhibited highest hydroxyl radical scavenging activity. With respect to the $\mathrm{EC}_{50}$ value, Rasthali leaf showed least value, which 
represent highest antioxidant activity. Statistically, the scavenging activity of antioxidants was effective in the order of Rasthali leaf $>$ Rasthali flower $>$ Rasthali stem $>$ Karpooravalli leaf $>$ karpooravalli flower $>$ karpooravalli stem.

Similar studies by Perez Capote et al. (2007) determined the scavenging effect of stem of Musa spp. on lipid peroxidation.

3.1.6 Superoxide radical scavenging activity

The superoxide radical scavenging assay is carried out to determine the ability of the banana peel extracts to scavenge free radicals by donating electrons. The greater the increase in percentage inhibition of superoxide radical, the greater the scavenging activity by the banana peel (Sakanaka and Tachibana 2006).

Figure 3.1.6.1. Scavenging activity (\%) on superoxide radical by ethanolic extracts of parts of Rasthali variety.

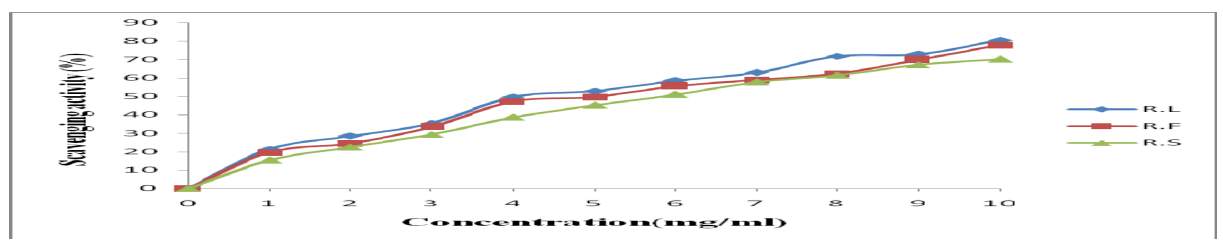

Figure 3.1.6.2. Scavenging activity (\%) on hydroxyl radical by ethanolic extracts of parts of Karpooravalli variety.

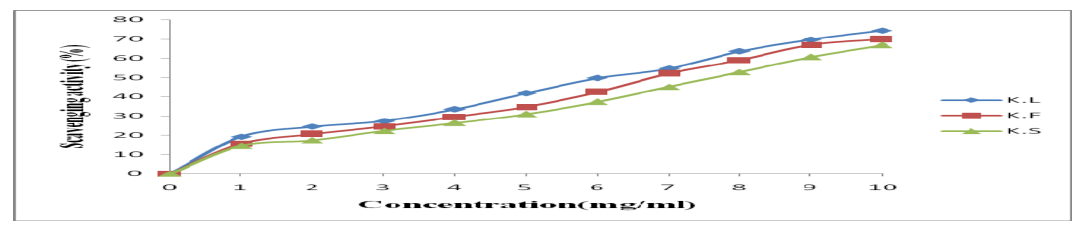

Figure 3.1.6.3 Comparison of EC50 values of superoxide radicals inhibition activity

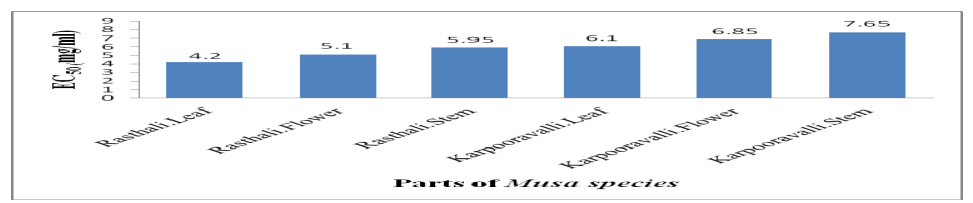

Free radical scavenging potential of the ethanolic extracts of parts of Musa spp is shown in Table 3.1.6.1 which increases with the increase in concentration

At $1-10 \mathrm{mg} \mathrm{ml}^{-1}$, the ethanolic extract of Rasthali leaf, flower, stem and karpooravalli leaf, flower, stem shows the percentage inhibition of $21.39 \%-80.46 \%, 19.61 \%-77.86 \%, 15.41 \%-70.21 \%, 19.30 \%-74.43 \%$, 15.59\%-69.88\%, 14.51\%-66.87\%, respectively. However, at $10 \mathrm{mg} \mathrm{ml}^{-1}$, Rasthali leaf extract exhibited highest superoxide radical scavenging activity. With respect to the $\mathrm{EC}_{50}$ value, Rasthali leaf showed least value, which represent highest antioxidant activity. Statistically, the scavenging activity of antioxidants was effective in the order of Rasthali leaf $>$ Rasthali flower $>$ Karpooravalli leaf $>$ Rasthali stem $>$ karpooravalli flower $>$ karpooravalli stem.

\subsubsection{Inhibition of lipid peroxidation activity}

Lipid peroxides, derived from polyunsaturated fatty acids, are unstable and decompose to form a complex series of compounds (Kulisic et al , 2006). These include reactive carbonyl compounds. The most abundant among them is malondialdehyde (MDA), one of the secondary lipid peroxidation products. These carbonyl products are responsible for DNA damage, generation of cancer and aging related diseases (Kulisic et $a l, 2006)$. Thus the decrease in the MDA levels in the presence of increased concentration of each extract indicates the role of extracts as antioxidants. TBARS assay was used to determine the anti-lipid peroxidation properties of the parts of Musa spp extracts. 
Figure 3.1.7.1. Scavenging activity (\%) on lipid peroxidation by ethanolic extracts of parts of Rasthali variety.

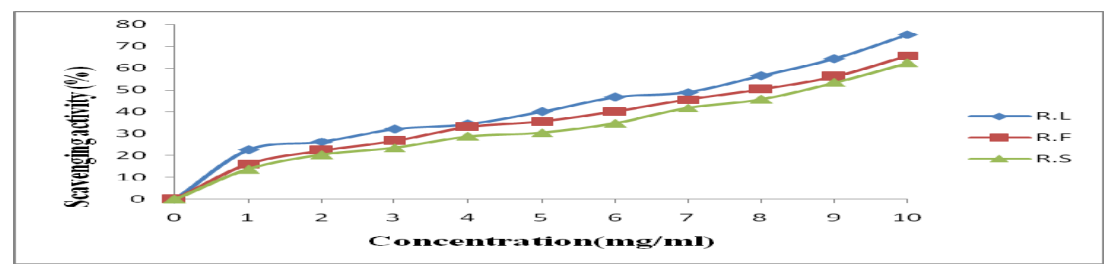

Figure 3.1.7.2. Scavenging activity (\%) on lipid peroxidation by ethanolic extracts of parts of Karpooravalli variety.

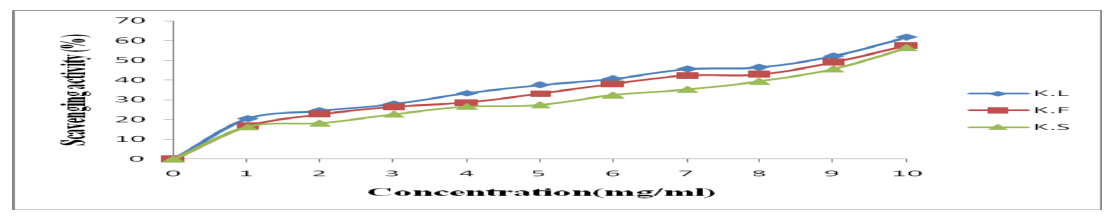

Figure 3.1.7.3 Comparison of EC50 values of lipid peroxidation inhibition activity

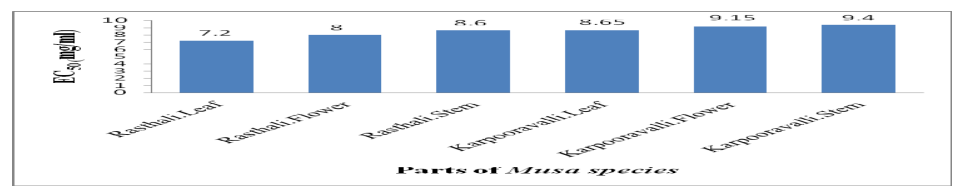

Free radical scavenging potential of the ethanolic extracts of parts of Musa spp is shown in Table 3.1.7.1 which increases with the increase in concentration

\subsubsection{Ferric Reducing Antioxidant Potential activity}

In this method, antioxidant compounds form a coloured complex with potassium ferricyanide, trichloro acetic acid and ferric chloride that was measured at $700 \mathrm{~nm}$. Increase in absorbance of the reaction mixture indicates the increase in the reducing power of the sample (Tenpe et al., 2008)

Figure 3.1.8.1 Reducing power of ethanolic extracts of parts of Rasthali variety

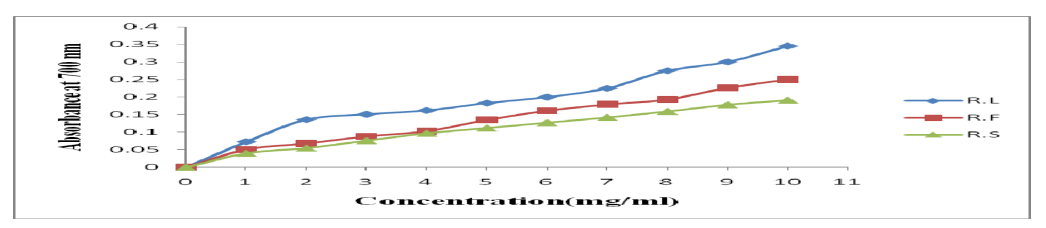

Figure 3.1.8.1 Reducing power of ethanolic extracts of parts of Karpooravalli variety

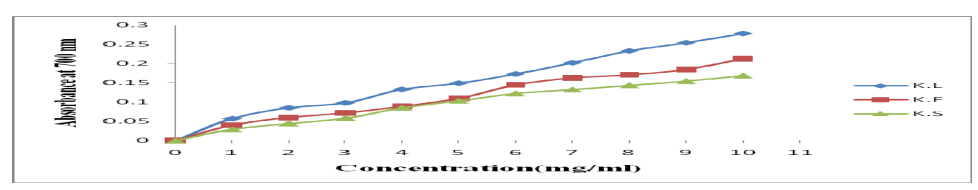

The reducing power of ethanolic extracts of parts of Musa spp. increases with the increase in concentration as depicted in the graph. The ethanolic extract of Rasthali leaf, flower, stem and karpooravalli leaf, flower, stem show the Mean absorbance of 0.073-0.345, 0.051-0.250, 0.040-0.191, 0.057-0.278, 0.040$0.213,0.029-0.168$ respectively. However, at $10 \mathrm{mg} \mathrm{ml}^{-1}$, Rasthali leaf extract exhibited highest reducing power.

Similar observation was made by (Kuo et al., 1999) which showed significant reducing power of parts of Musa spp. 
Figure 3.1.8.1 Reducing power of ethanolic extracts of parts of Rasthali variety

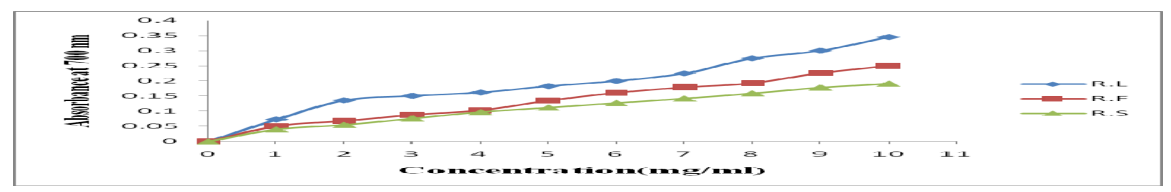

Figure3.1.8.2 Reducing power of ethanolic extracts of parts of Karpooravalli variety

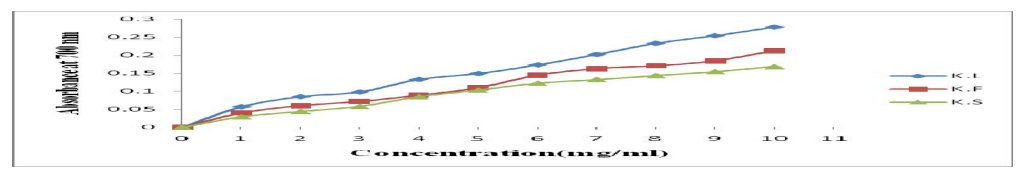

The reducing power of ethanolic extracts of parts of Musa spp. increases with the increase in concentration as depicted in the graph. The ethanolic extract of Rasthali leaf, flower, stem and karpooravalli leaf, flower, stem show the Mean absorbance of 0.073-0.345, 0.051-0.250, 0.040-0.191, 0.057-0.278, 0.040$0.213,0.029-0.168$ respectively. However, at $10 \mathrm{mg} \mathrm{ml}^{-1}$, Rasthali leaf extract exhibited highest reducing power.

Similar observation was made by (Kuo et al., 1999) which showed significant reducing power of parts of Musa spp.

Figure 3.1.9.3 Comparison of EC50 values of $\beta$-carotene bleaching activity.

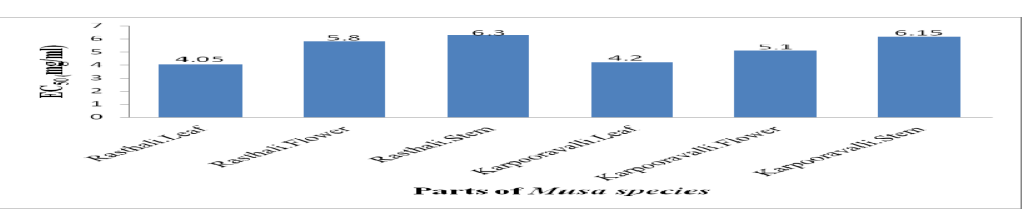

Free radical scavenging potential of the ethanolic extracts of the parts of Musa spp is shown in Table 3.1.9.1 which increases with the increase in concentration

At $1-10 \mathrm{mg} \mathrm{ml}^{-1}$, the ethanolic extract of Rasthali leaf, flower, stem and karpooravalli leaf, flower, stem show the percentage inhibition of $30.39 \%-88.85 \%, 27.21 \%-84.31 \%, 24.47 \%-80.51 \%, 25.30 \%-84.07 \%$, $24.27 \%-79.84 \%, 21.77 \%-74.65 \%$ respectively. However, at $10 \mathrm{mg} \mathrm{ml}^{-1}$, Rasthali leaf extract exhibit highest activity. With respect to the $\mathrm{EC}_{50}$ value of Rasthali leaf showed the least value, which represent highest $\beta$ carotene bleaching inhibition activity. Statistically, the scavenging activity of antioxidants was effective in the order of Rasthali leaf $>$ Rasthali flower $>$ Karpooravalli leaf $>$ Rasthali stem $>$ Karpooravalli flower $>$ Karpooravalli stem.

\subsection{Enzymatic antioxidants} Musa spp.

Table3..2.1 represents the activities of superoxide dismutase and catalase activities in different parts of

SOD catalyses the conversion of superoxide anion radical into hydrogen peroxide, removes singlet oxygen as well as prevents formation of $\mathrm{OH}$, and has been implicated as an essential defense against the potential toxicity of oxygen.

Catalase is frequently used by cells to rapidly catalyze the decomposition of hydrogen peroxide into less reactive gaseous oxygen and water molecules. Human catalase works at an optimum temperature of $37^{\circ} \mathrm{C}$. Values represent mean $\pm \mathrm{SD}$ of 3 replicates.

Means ranked by a common letter are not significantly different at the $5 \%$ level by DMRT.

Units: $\quad$ SOD $-50 \%$ inhibition of nitrate $\mathrm{min}^{-1} \mathrm{mg}_{\text {protein }}{ }^{-1}$.

CAT - n moles of $\mathrm{H}_{2} \mathrm{O}_{2}$ decomposed $\mathrm{min}^{-1}$ mg protein ${ }^{-1}$.

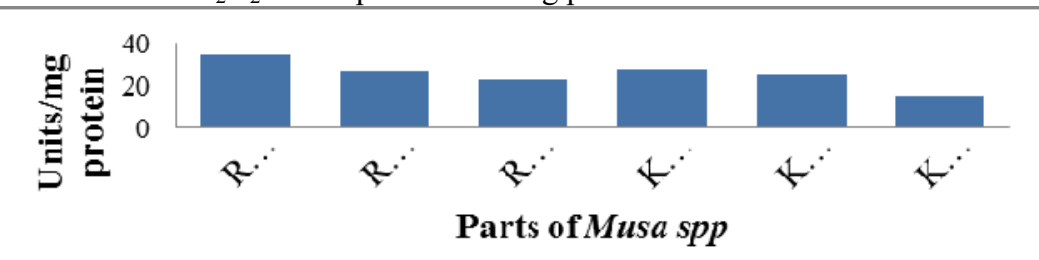

Fig. 3.2.1. Activity of superoxide dismutase in different parts of Musa spp. 


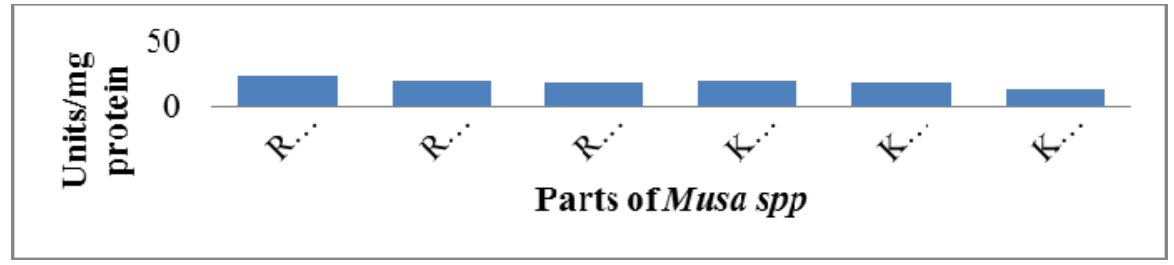

Fig. 3.2.2. Activity of catalase in different parts of Musa spp.

The biochemical function of glutathione peroxidase is to reduce lipid hydroperoxides to their corresponding alcohols and to reduce free hydrogen peroxide to water. GST offers protection against lipid peroxidation by promoting the conjugation of toxic electrophiles with GSH (Jakoby, 1988). GR maintains the cellular levels of GSH (by the reduction of GSSG), which protects the cellular membranes from peroxides.

Values represent mean $\pm \mathrm{SD}$ of 3 replicates.

Means ranked by a common letter are not significantly different at the $5 \%$ level by DMRT.

Units: $\quad \mathrm{GPX}-\mathrm{n}$ moles of GSH consumed $\mathrm{min}^{-1} \mathrm{mg}_{\text {protein }}{ }^{-1}$.

$\mathrm{GR}-\mu$ moles of GSH utilized $\mathrm{min}^{-1} \mathrm{mg}_{\text {protein }}{ }^{-1}$.

GST - $\mu$ moles of CDNB-GSH conjugate formed $\min ^{-1} \mathrm{mg}$ protein ${ }^{-1}$.

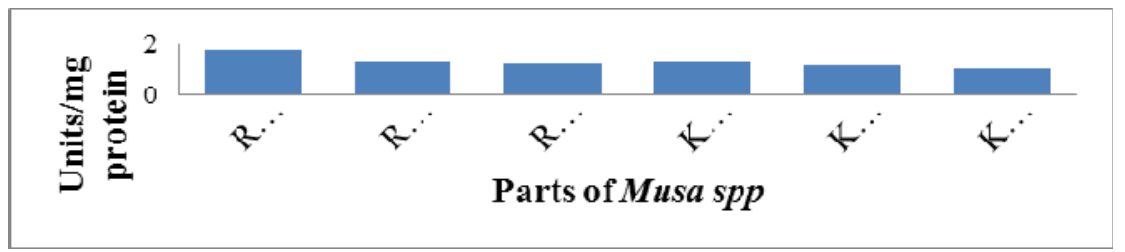

Fig. 3.2.3. Activity of glutathione peroxidase in different parts of Musa spp.

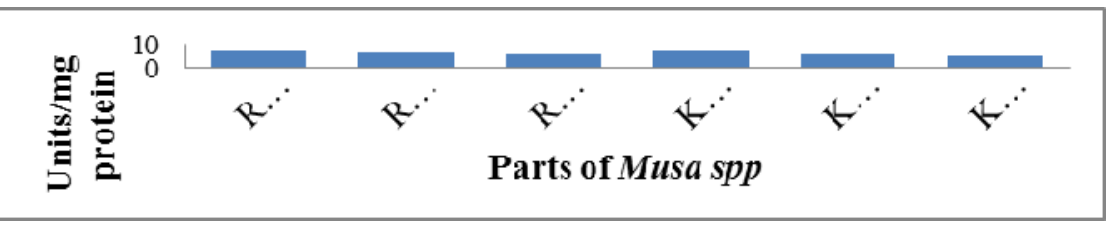

Fig. 3.2.4. Activity of glutathione-S-transferase in different parts of Musa spp.

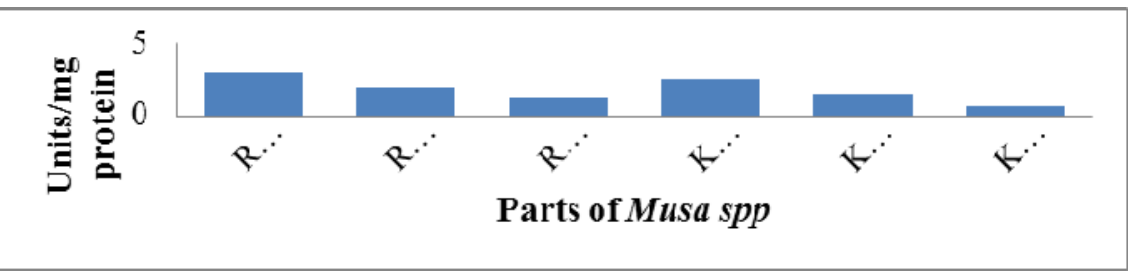

Fig.3.2.5. Activity of glutathione reductase in different parts of Musa spp.

G6PD is a cytosolic NADP dependent enzyme. This generates NADPH which is necessary for the regeneration of reduced glutathione from oxidized GSH. Maintenance of GSH in the reduced state is an important function of G6PD.

Values represent mean $\pm \mathrm{SD}$ of 3 replicates.

Means ranked by a common letter are not significantly different at the $5 \%$ level by DMRT.

Units: G6PD, PPO - 0.01OD $\mathrm{min}^{-1} \mathrm{mg}_{\text {protein }}{ }^{-1}$.

Polyphenol oxidase is an oxygen transferring enzyme. PPO in the presence of oxygen, catalyses the oxidation of phenolic compounds to form corresponding quinine intermediates which polymerise to form undesirable pigments. The enzyme catalyses two types of oxidative reactions: the hydroxylation of monophenols to o- diphenols, and the oxidation of o- diphenols to o- quinines. 
G6PD activity in banana varieties ranged between 0.781 to 0.409 units mg protein ${ }^{-1}$. Rasthali leaf again topped the list among all varieties. Hence, it helps in efficient regeneration of reduced glutathione by maintaining NADPH levels. Reduced glutathione in turn forms conjugate with free radicals thereby combating several diseases. On the contrary, least G6PD activity was observed in Karpooravalli stem. PPO activity was highest in Rasthali leaf extract, the least being in Rasthali.

\subsection{Non- Enzymatic antioxidants}

Table 3.3.1 represents total reduced glutathione, vitamin E, Ascorbic acid contents in different parts of Musa spp.

Ascorbic acid functions as the main water-soluble antioxidant protecting tissue from oxidative damage. It acts as a direct scavenger of free radicals and acts as a reductant in enzymatic reactions.

Values represent mean \pm SD of 3 replicates.

Means ranked by a common letter are not significantly different at the $5 \%$ level by DMRT.

Units: Ascorbic acid, Total GSH $-\mathrm{mg} \mathrm{g}^{-1}$ fresh tissue

Vitamin $E-\mu g \alpha$ - tocopherol equivalents $g^{-1}$ fresh tissue.

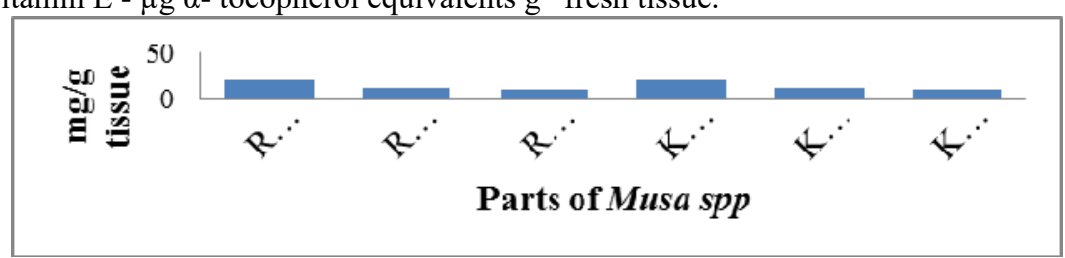

Fig. 3.3.1. Total reduced glutathione content in different parts of Musa spp.

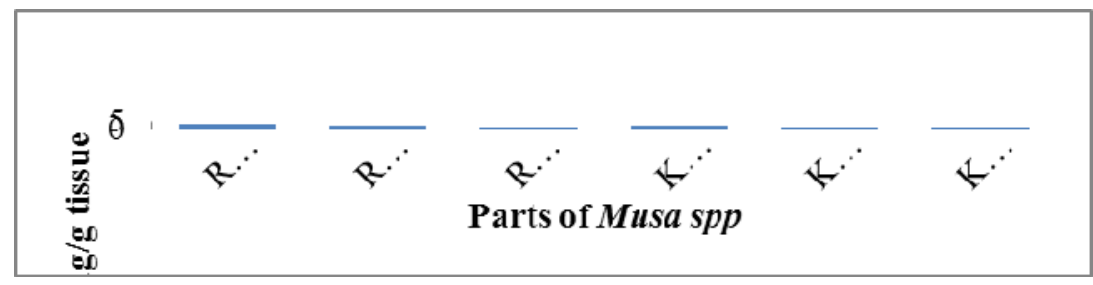

Fig.3.4.3.2. Vitamin C content in different parts of Musa spp.

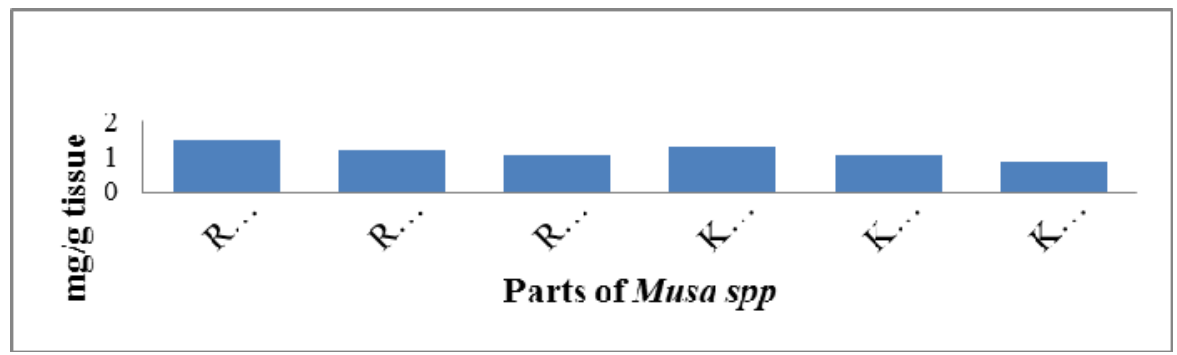

Fig. 3.3.3. Vitamin E content in different parts of Musa spp.

\subsection{Phytochemicals}

Table.3.4.1. represents the activities of Total Phenolics, Flavonoid and Alkaloid contents in different parts of Musa spp.

Phenolic compounds, among others flavonoids and phenolic acids, depict antioxidant and antiradical activities in vitro. There is evidence that phenolic compounds can also act as antioxidants and scavengers of free radicals in vivo. The antiradical and antioxidant effects of phenolic compounds in vivo may slow down the ageing processes as well as protect the human body against diseases such as atherosclerosis, coronary heart disease and cancer

Values represent mean $\pm \mathrm{SD}$ of 3 replicates.

Means ranked by a common letter are not significantly different at the $5 \%$ level by DMRT.

Units: Total Phenols $-m g$ catechol equivalents $\mathrm{g}^{-1}$ fresh tissue.

Flavonoids $-\mathrm{mg}$ rutin equivalents $\mathrm{g}^{-1}$ fresh tissue.

Alkaloids - mg theophylline equivalents $\mathrm{g}^{-1}$ fresh tissue. 


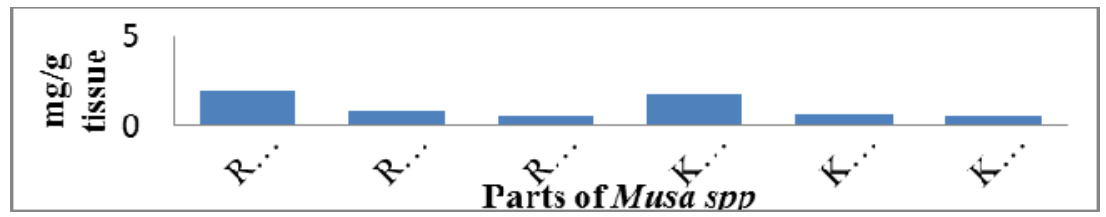

Fig.3.4.1. Total Phenols Content in different parts of Musa spp.

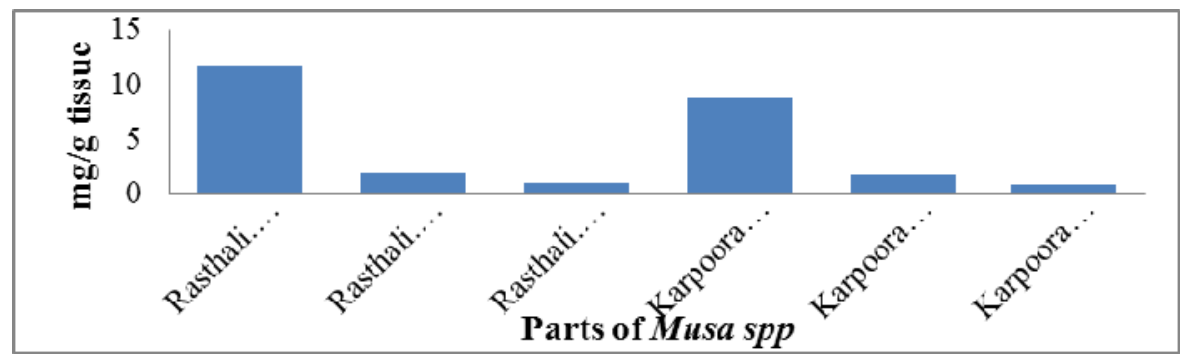

Fig. 3.4.2. Flavanoids Content in different parts of Musa spp.

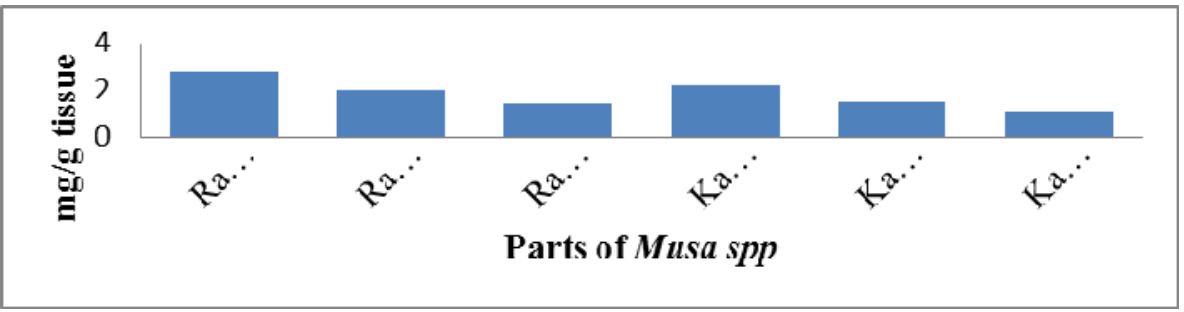

Fig. 3.4.3. Alkaloids Content in different parts of Musa spp.

Table.3.4.1 depicts the activities of carotenoids and lycopene contents in different parts of Musa spp. Values represent mean \pm SD of 3 replicates.

Means ranked by a common letter are not significantly different at the $5 \%$ level by DMRT.

Units: Carotenoids, Lycopenes $-\mathrm{mg} \mathrm{g}^{-1}$ fresh tissue

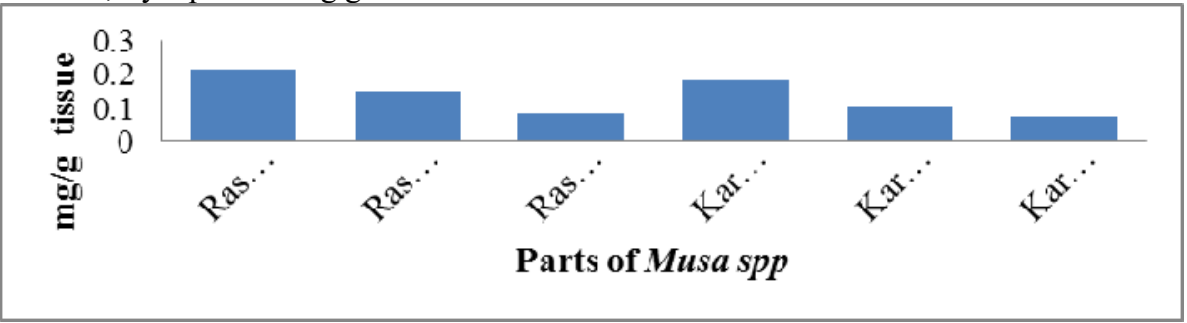

Fig. 3.4.5 Carotenoid Content in different parts of Musa spp.

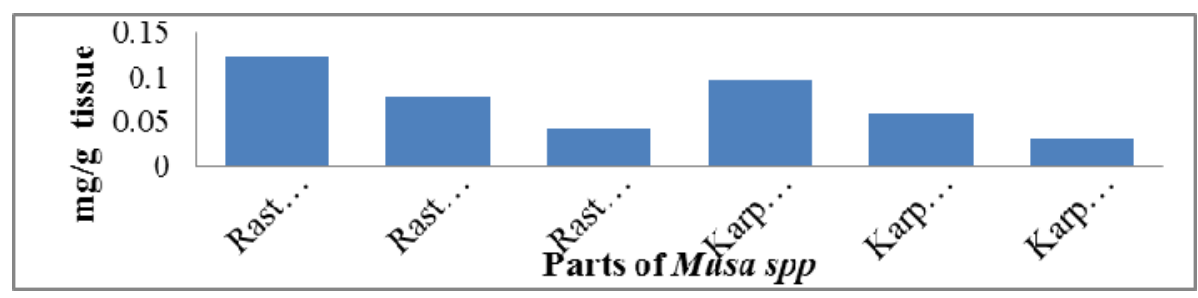

Fig. 3.4.6. Lycopene Content in different parts of Musa spp. 


\section{CONCLUSION}

Antioxidants are substances that may protect cells from the damage caused by unstable molecules known as free radicals. Free radical damage may lead to cancer. Antioxidants interact with and stabilize free radicals. Antioxidants are compounds in fruits and vegetables, which help in avoiding chronic diseases. They act as a defense system against oxidative damage in our bodies and may help in avoiding chronic diseases. The present work has been undertaken to evaluate and hence compare the antioxidant potential of three parts of banana varities, namely, Rasthali leaf, Rasthali stem, Rasthali flower, Karpooravalli leaf, Karpooravalli stem, Karpooravalli flower. The free radical scavenging ability of the parts of the Musa spp were tested against various free radicals generated in vitro and the results obtained. The parts extracts of Musa spp were assayed for different enzymatic, non- enzymatic and phytochemical compounds like SOD, GPx, GR, Vitamin C, Vitamin E, carotenoids, alkaloids, total phenols, flavonoids etc. The results obtained were subjected to two- way ANOVA and the parts of the varieties were ranked according to their antioxidant and phytochemical content. Even though all parts of the varieties showed significant antioxidant and phytochemical potential, Rasthali leaf, Karpooravalli leaf showed highest antioxidant and phytochemical potential. On the whole, all parts of banana varieties exhibited a good antioxidant activity with leaf part topping the list.

The main objective of this study was to evaluate and compare the antioxidants and phytochemical potentials in the parts extracts of Musa spp.

\section{REFERENCES}

[1] Abdelmalek, M. Angulo, P. Jorgensen, R.B. (2000) 'Betaine for patients with non-alcoholic steatohepatitis: a promising new agent', Gastroenterology, Vol.118, pp.973A.

[2] Ajay Sharma, Sudhir Bhardwaj, Amit Jain, Mann.A.S. and Kharya.M.D., (2007). Screening methods of Antioxidant activity: An overview, Pharmacognosy Reviews,Vol.1, pp. 232-238.

[3] Amalia Ubeda, Carmen Montesinos, Miguel Payá, Carmen Terencio, Maria Jose Alcaraz, and Halliwell, B. (1993) 'Antioxidant Action of Benzylisoquinoline Alkaloids', Free Radical Research Vol.18, pp.167-175.

[4] Bagchi, K. and Puri, S. (1998) 'Free radicals and antioxidants in health and disease', Eastern Mediterranean Health Journal,Vol.4, pp.350-360.

[5] Balinsky, D. and Bernstein, R.E. (1963) 'The purification and properties of glucose-6-phosphate dehydrogenase from human erythrocytes', Biochemica et Biophysica Acta, Vol.67, pp.13-15

[6] Bjelakovic, G. Nikolova, D. Gluud, LL. Simonetti, RG. and Gluud, C. (2007) 'Mortality in randomized trials of antioxidant supplements for primary and secondary prevention: systematic review and meta-analysis', JAMA Vol.297(8), pp.842-57.

[7] Bannister, J. Bannister, W. and Rotilio, G. (1987) 'Aspects of the structure, function, and applications of superoxide dismutase', CRC Crit Rev Biochem, Vol.22 (2), pp.111-80.

[8] Benzie, I.F.F. and Strain, J.J. (1996) 'The ferric reducing ability of plasma (FRAP) as a measure for "Antioxidant Power;The FRAP assay’, Anal Biochem, Vol.239,pp.70-76.

[9] Bannister, J. Bannister, W. and Rotilio, G. (1987) 'Aspects of the structure, function, and applications of superoxide dismutase', CRC Crit Rev Biochem Vol.22(2), pp.111-80.

[10] Beutler, E. (1984) 'Glutathione in red blood cell metabolism. A manual biochemical methods', Steril.,Vol.68, pp.907-911.

[11] Bisseling, J.G.A. Knapen, M.F.C.M. Goverde, H.J.M. Mulder, T.P.J. Peters, W.HM. Willemsen, W.N.P. Thomas, C.M.G. and Steegers, E.A.P. (1997) 'Glutathione S-transferases in human ovarian follicular fluid', Fertil. Steril., Vol.68, pp.907-911

[12] Brigelius,F. R. and Traber, M. (1999). 'Vitamin E: function and metabolism'. FASEB J, Vol.13 (10), pp.1145 - 55

[13] Candelaria del Mar Verde Méndez, Markus Paul Forster, Miguel Ángel Rodríguez-Delgado, Elena María Rodríguez-Rodríguez and Carlos Díaz Romero (2004). 'Content of free phenolic compounds in bananas from Tenerife (Canary Islands) and Ecuador', European Food Research and Technology Vol.217, pp.287-290

[14] Cansin, Sackesen, Hulya E.Evrim,D. Ozge,S. Pinar gumus, and Omer,K.(2008), 'A comprehensive evaluation of the enzymatic and nonenzymatic antioxidant systems in childhood asthma', Cardiovascular prevention and rehabilitation,Vol.122, pp.78-85. 